\title{
An important step towards smarter screening for prostate cancer
}

The WHO reminds us that screening starts with a 'rough sorting process', to identify those at higher risk of the target condition, followed by a diagnostic test, to determine whether the condition is present ${ }^{1}$. Nordstrom and colleagues are to be congratulated on their prostate cancer screening study, using a paired design for novel approaches at the first sort and then randomisation between standard biopsy and an MRI-first arm at the diagnostic test stage ${ }^{2}$.

The European Randomised Screening for Prostate Cancer (ERSPC) is the only screening study to have shown a prostate cancer mortality reduction, with a $20 \%$ reduction at 16 year follow $u^{3}$. However, this comes at a cost of significant overdiagnosis, and subsequent overtreatment, which have been a major barrier to adoption of formal prostate cancer screening. The ERSPC used digital rectal examination and the prostate specific antigen (PSA) blood test as the 'sorting' tests for men deemed at risk due to age, with standard transrectal biopsy as the diagnostic test for men who tested positive either on DRE or with a PSA of $\geq$ $3 \mathrm{ng} / \mathrm{ml}$.

Nordstrom and colleagues have used a more complex initial first test, the Stockholm 3 risk calculator (STHLM3), which incorporates age, previous biopsy history, PSA derivatives and polygenic risk score based on a single nucleotide protein (SNP), and compared it to a PSA threshold of $\geq 3 \mathrm{ng} / \mathrm{ml}$, with the STHLM3 showing an AUC of 0.76 for clinically significant cancer compared to 0.6 for PSA alone in this study. It is interesting that DRE has been omitted entirely in this study, and helpful as we progress towards a modern screening approach. Men were then randomised in a 2:3 manner to standard transrectal biopsy or MRI, with targeted and standard biopsy for any men with an MRI score of 3-5.

Eklund has recently published the findings from the same study, showing that $\mathrm{MRI}+/-$ targeted biopsy in this setting, when men are selected by a PSA threshold of $\geq 3 \mathrm{ng} / \mathrm{ml}$ alone, is non-inferior in the detection of clinically significant disease to standard biopsy, whilst allowing $60 \%$ of men to avoid biopsy, and reducing over-detection of indolent disease from $12 \%$ to $4 \%{ }^{4}$. This finding in a screening population complements the PRECISION finding that $\mathrm{MRI}+/$ - targeted biopsy is superior to standard biopsy in a clinically selected population, where background risk and mean PSA are higher than in a screening population ${ }^{5}$.

Nordstrom \& colleagues have demonstrated in this paper that there is equivalent detection of clinically significant cancer for an STHLM3 threshold of 0.15 , compared to PSA $\geq 3 \mathrm{ng} / \mathrm{ml}$, whilst reducing the need for MRI by one third, and biopsy by $8 \%$. The novel paired sorting test, with minimal additional patient burden, and randomised diagnostic test allows assessment of both strategies. The economic impact of novel screening and diagnostic tools must be addressed. A recent analysis showed that compared to age based, biopsy first screening (such as in ERSPC), a risk stratified MRI first strategy would not only result in fewer prostate cancer deaths, fewer biopsies and fewer overdiagnoses, but also be cost effective ${ }^{6}$. 
A number of factors will contribute to the success or otherwise of a screening programme, including uptake of the invitation, test performance of both screening and diagnostic tools, and the ability of treatment to reduce mortality.

This study showed $26 \%$ uptake of the screening invitation, compared to $32 \%$ uptake of the ERSPC invitation in the Netherlands at the outset, increasing to $42 \%$ over time ${ }^{7}$. Formal national screening programmes aim for uptake of $70-80 \%$ uptake. The authors do not report the uptake of the invitation across different parts of the community. However, current data shows that black men, who are at increased risk of prostate cancer, may be less likely to take up an invitation for prostate cancer screening ${ }^{8}$. A combination of interventions may be appropriate to increase uptake ${ }^{9}$, and the potential increase in acceptability in removing the need for digital rectal examination seems likely to contribute to a willingness to be screened across many communities.

A further challenge is the implementation of high quality MRI for all, as this is significantly more challenging than standard TRUS biopsy ${ }^{10}$. Implementation requires a co-ordinated approach across a number of departments including imaging, urology and histopathology, and may include a formal quality assurance and quality control programme, with accreditation by professional bodies.

This study has shown advantages over the traditional PSA and standard biopsy approach, in both the initial 'sort' test and the diagnostic test. Further work will be needed to assess the generalisability and cost-effectiveness of this approach.

Word count $750 / 750$ 


\section{References}

1. Screening programmes: a short guide. Increase effectiveness, maximize benefits and minimize harm. Copenhagen: WHO Regional Office for Europe; 2020. Licence: CC BYNC-SA 3.0 IGO.

2. Prostate cancer screening using a combination of risk-prediction, magnetic resonance imaging and targeted prostate biopsies: results from the populationbased STHLM3MRI trial. THELANCET ONCOLOGY-D-21-00807R1

3. Hugosson J, Roobol MJ, Månsson M, et al. A 16-yr follow-up of the European Randomized study of Screening for Prostate Cancer. Eur Urol 2019;76:43-51.

4. Eklund $M$, Jaderling $F$, Discacciati $D$, Bergman $M$, Annerstedt $M$, Alya $M$, Glaessgen A, Carlsson S, Gronberg H, Nordstrom T, for the STHLM3 consortium. MRI-targeted or standard biopsy in prostate cancer screening. N Engl J Med2021 Jul 9. doi: 10.1056/NEJMoa2100852. Online ahead of print.

5. Kasivisvanathan V, Rannikko AS, Borghi M, Panebianco V, Mynderse LA, Vaarala MH, Briganti A, Budäus L, Hellawell G, Hindley RG, Roobol MJ, Eggener S, Ghei M, Villers A, Bladou F, Villeirs GM, Virdi J, Boxler S, Robert G, Singh PB, Venderink W, Hadaschik BA, Ruffion A, Hu JC, Margolis D, Crouzet S, Klotz L, Taneja SS, Pinto P, Gill I, Allen C, Giganti F, Freeman A, Morris S, Punwani S, Williams NR, Brew-Graves C, Deeks J, Takwoingi Y, Emberton M, Moore CM; PRECISION Study Group Collaborators. MRI-Targeted or Standard Biopsy for Prostate-Cancer Diagnosis. N Engl J Med. 2018 May 10;378(19):1767-1777. doi: 10.1056/NEJMoa1801993. Epub 2018 Mar 18.PMID: 29552975

6. Callender T, Emberton M, Morris S, Pharoah PDP, Pashayan N. Benefit, Harm, and Cost-effectiveness Associated With Magnetic Resonance Imaging Before Biopsy in Age-based and Risk-stratified Screening for Prostate Cancer.JAMA Netw Open. 2021 Mar 1;4(3):e2037657. doi: 10.1001/jamanetworkopen.2020.37657.PMID: 33704474

7. Nijs HGT,Tordoir DMR, Schuurman JH, Kirkels WJ, Schroder FH. Randomised trial of prostate cancer screening in the Netherlands: assessment of acceptance and motives for attendance. Journal of Medical Screening 1997;4:102-106

8. Carthon B, Sibold HC, Blee S, Pentz RD. Prostate Cancer: Community education and Disparities in Diagnosis and Treatmnet. Oncologist $2021 \mathrm{Jul} ; 26(7): 537-548$. doi: 10.1002/onco.13749. Epub 2021 Mar 22.

9. Duffy, SW, Myles JP, Maroni R, Mohammad A. Rapid review of evaluation of interventions to improve participation in cancer screening services. J Med Screen 2017 Sep;24(3):127-145. doi: 10.1177/0969141316664757. Epub 2016 Oct 17.

10. Giganti F, Allen C, Emberton M, Moore CM, Kasivisvanathan V; PRECISION study group.Prostate Imaging Quality (PI-QUAL): A New Quality Control Scoring System for Multiparametric Magnetic Resonance Imaging of the Prostate from the PRECISION trial. Eur Urol Oncol. 2020 Oct;3(5):615-619. doi: 10.1016/j.euo.2020.06.007. Epub 2020 Jul 6.PMID: 32646850 